\title{
Situation awareness as a determinant for unsafe actions and subjective risk assessment on offshore attendant vessels
}

\author{
Bjøm Sætrevik ${ }^{1,2} \&$ Sigurd W. Hystad ${ }^{1,3}$
}

\begin{abstract}
1: Operational Psychology Research Group, Department of Psychosocial Science, Faculty of Psychology, University of Bergen, Christies gate 12, NO-5015 Bergen.

2: Email: bjorn.satrevik@uib.no, corresponding author

3: Email: sigurd.hystad@ uib.no
\end{abstract}

\begin{abstract}
Situation awareness (SA) is often argued to be a "sharp end" indicator of workplace safety, in the sense that inaccurate SA may be the proximal cause for operator error. However, traditional field or lab experiment measures of SA are difficult to combine with large-scale data collections to examine organizational influences on SA and the safety outcomes of SA. In the current study, offshore attendant vessel crew's SA was measured with a self-report scale. Authentic leadership was modelled as a predictor, while self-report of committing unsafe actions at work and subjective risk assessment were modelled as outcome measures. Structural equation modelling showed the captain's leadership style to account for variation in SA and some variation in unsafe actions. Further, SA accounted for variation in unsafe actions and in subjective risk assessment. The study supports the assumption that SA has a crucial role in maritime safety.
\end{abstract}

\section{Keywords}

Safety; Situation awareness; Authentic leadership, Risk assessment; Structural equation modelling

\section{1: Introduction}

1.1: Accidents in the maritime industry

Safety is a major concern in the petro-maritime industry due to accidents having potential for catastrophic consequences. The International Association of Oil and Gas Producers (2014) reported that the total recordable incident rate (TRIR, calculated per 1000000 man hours worked) in the offshore sector worldwide was 2.34 in 2013. While the types of accidents and potential consequences vary greatly, collisions between vessel and offshore installation are often regarded as a worst-case scenario, due to both vessel and installation being at risk, in terms of human causalities, economic loss, and maritime and coastal pollution (Flin et al., 1996). Between 2001 and 2010, 175 such collisions were reported in the Gulf of Mexico sector (Bureau of Safety and Environmental Enforcement, 2016). In the same time window, twenty-six collisions were reported on the Norwegian continental shelf, of which at least 
six were considered to have catastrophic potential (Kirschenbaum et al, 2000). Other types of incidents, such as fire, loss of propulsion or crane accidents, can also have serious consequences for the vessel and its crew.

In the organization where the current data collection took place, around 70 vessels attend about 55 offshore installations (subject to variations in operational demands) from seven different ports. In 2014, the organization recorded 57 incidents that led to injuries. While most were minor injuries, two were classified as having the potential for serious injury or death. This yields a TRIR of 1.26 for injuries in 2014. In addition, there were 20 incidents of vessels on a collision course with an installation, and two incidents of contact between vessel and installation.

\section{2: Aims for study}

Unwanted events take place in a complex interplay of technological, individual, and organizational factors (Dekker et al., 2010; Reason, 1990). Keeping this in mind, it may nevertheless be useful to examine the operator's behaviour as the immediate precondition for incidents. That is to say, the operator's action (or inaction) can be the proximal cause of an incident, although the action itself has other distal causes. The operators' cognitions are assumed to influence their actions, decisions and habits in ways that affect safety. The aim of the current study was to identify factors that predict safety and that can be subject to interventions from the ship-owner or the chartering company. The captain may have a key role in enforcing the organization's expected safety level on the vessel, and the captain's leadership style may be more or less suited to achieve this. Thus, our study addresses how safety is impacted by the overview that crewmembers have of the safetycritical aspects of their work-environments, and the kind of leadership that captains are offering in their daily interactions with the crew. Other factors, such as the structure of the work-task, task-load, stressors, workplace design, availability of tools, co-worker qualities, team-work, social support and communication, will also contribute to the operator's safety behaviour, but may be more challenging to measure through self-report, and to address by organizational interventions.

\section{3: Proposed relationships impacting safety}

In the present study, we wanted to examine how situation awareness and authentic leadership combine to influence safety-related outcome variables in terms of the crewmembers' risk assessment and whether they engage in unsafe actions. A cross-sectional self-report survey was performed among the operators of vessels on hire for a single hydrocarbon producing company. Possible mechanisms of interaction between the measured variables are discussed below and summarized in Figure 1.

\subsection{1: Situation awareness and safety}

The concept of situation awareness (SA) refers to having an accurate representation of the crucial factors of your environments (Endsley, 2004; Sarter and Woods, 1991). SA develops as a result of a recurrent assessment of and interaction with one's surrounding, and feeds into the decision-making. SA is often described (see e.g. Endsley, 1995) as consisting of three different processes or levels of information; the perception of elements in the environment (level 1SA), the comprehension of the situation (level $2 \mathrm{SA}$ ), and the projection of the situation into the near future (level 3 SA).

It should be noted that Endsley's (1995) threelevel model has been questioned on epistemological, cognitive, pragmatic, and methodological grounds (Hone et al., 2006; Patrick and Morgan, 2010; Rousseau et al., 2010; van Winsen and Dekker, 2015). There are also competing theoretical accounts, such as situated SA (Chiappe et al., 2012), which argues that in addition to internal states, the operators also use cognitive elements embedded in the environment, distributed SA (Stanton et al., 2015), which focuses on the sociotechnical system rather than the individual operator's cognitions, and sensemaking (Klein et al., 2006), which describes a two-way process of fitting observations and mental model to each other. 
Since SA influences performance and decisionmaking, it has been argued that SA has a crucial role in safety (Flin et al., 2008). In a given safety challenge, operators that have accurate SA may safely resolve an issue that would have led to an accident among operators with less accurate SA. One mechanism through which SA influe nces safety, may be that operators that have a poor overview of the safety aspect in their work are less able and motivated to work safely (and thus perform more unsafe actions). A number of factors have been suggested to determine the operator's SA, both individual, social, environment and task factors (Endsley and Jones, 2013). A suitable workenvironment on board the vessel may be one that presents the information that the crewmembers need to work safely in an accessible, timely and understandable manner. In the current study, we focus on how SA may be influenced by the way the captain's leadership style encourages and inspires the crew to establish accurate SA.

\subsection{2: Authentic leadership and safety}

We propose that the captain's leadership qualities can create a climate for being mindful of safety and motivate the operator to take safety seriously. The concept of authentic leadership (AL) describes a relationship that is characterized by "a) transparency, openness, and trust, b) guidance toward worthy objectives, and c) an emphasis on follower development" (Gardner et al., 2005, p. 345). Gardner and colleagues (2005) suggested that more authentic leaders will create organizational climates that are oriented towards developing strengths, and that are characterized by inclusiveness and commitment. Within safety critical industries, more authentic leaders should therefore be expected to create climates that prioritize safety. This proposition has been supported by previous research within the petromaritime industry. For instance, Nielsen et al. (2013) showed that follower ratings of AL in highreliability organizations were associated with perceiving risks to be low, and with positive ratings of safety climate. Similarly, Hystad et al. (2014) demonstrated that AL exerted a direct influence on ratings of safety climate, as well as an indirect influence through increasing core psychological resources in followers. A further suggestion tested in the current study, is that AL may increase safety through the captain's encouraging and inspiring the crew to work in a way that allows them to establish accurate SA.

\subsection{3: Safety outcomes}

We wanted to examine the impact of AL and SA on safety-related outcome variables. Serious accidents in the petro-maritime industry are thankfully too rare for us to use the number of accidents occurring within a data collection period as an outcome measure. Accidents of smaller consequences or "near-misses" are more frequent and there is usually a reporting system in place to measure them. However, there is some uncertainty as to the reliability of the reporting (Probst et al., 2008; Weddle, 1996), and to whether the frequency of reporting minor accidents corresponds to the objective level of risk for serious accidents (Rundmo, 1996). Further, the contractual relationships between the parties involved in our data collection prevented us from associating our survey measure to objective measures of reported incidents.

In the current study, we ask respondents to answer a scale of items about the extent to which they engaged in unsafe actions at work, or were "cutting corners" in their adherence to the safety regiment. We assume that performing such actions increase the likelihood of accidents occurring, and hence use this as a safety outcome measure. Crew members who are subject to poor leadership from their captain may be less motivated to or less able to follow the safety management system and commit more unsafe actions (see e.g. Clarke, 2013, for a review). Further, crew members with a poor SA may perform more unsafe actions due to inattention, lack of knowledge or resources (Sneddon et al., 2006b).

As an additional outcome measure, we asked the respondents to indicate what likelihood they believed various types of accidents had of occurring in the next 12 months, which constitutes a subjective risk assessment. While similar measures are sometimes referred to as "risk perception", we find 
this term to have unfortunate connotations to cognitive psychology (that it reflects a perceptual process) and to normativity (that there is an objective level of risk that the respondent can assess more or less accurately). The crew's subjective assessment of the level of risk could to some extent reflect the actual safety. Previous studies have found that workers can have accurate assessments of risks in the workplace (Flin et al., 1996), and that the assessment is associated with accident involve ment (Kirschenbaum et al., 2000; Rundmo, 1996). Crew members who feel they sometimes lose control of the safety aspects of their work (i.e. having inaccurate SA) may correctly perceive their work as more risky (Sneddon et al., 2006a). Self-report studies of risk-perception (Rundmo, 1996) have indicated a complex relationship between offshore operator's subjective assessment of risk and the actual risk for accidents, where the two factors are associated although the causal direction is unclear. Our approach bears some similarities to a study by Sneddon, Mearns and Flin (2013), where selfreports from offshore drillers showed SA to be predicted by stress and recent accidents, and to be associated with performing unsafe actions.

\section{4: Hypotheses}

The relationships between the concepts outlined above may be summarized in four hypotheses: Being aware of the safety aspects of your environments should reduce dangerous behaviour, leading us to expect (H1) increase in $S A$ to be associated with a decline in unsafe actions. Being confident that you can understand and control the safety aspects of your environments would lower your rating of the chance of dangerous situations evolving, leading us to expect $(\mathrm{H} 2)$ increase in $S A$ to be associated with decrease in subjective risk assessment. A captain that is seen as genuinely expressing and encouraging safety should increase the operator's safe work-behaviour, leading us to expect (H3) increase in $A L$ to be associated with decline in unsafe actions. To reflect the positive effects of leadership on the operator's awareness of workplace safety, we expect (H4) increases in $A L$ to be associated with increases in $S A$.

\section{2: Methods}

2.1: Participants and procedure

A survey was sent out to all the vessels on hire to a major hydrocarbon production company, for a total of 63 vessels. As the crewing of each vessel was expected to vary between five and fifteen members, each vessel received thirty copies of the survey for its two alternating crews. Thus a total of 1890 survey copies were sent out, although there are not that many potential respondents. Each survey was accompanied with a postage-paid return envelope addressed to the researchers at the university.

A total of 844 valid surveys were returned, received from 49 of the 63 vessels. Thus no surveys were returned from fourteen of the vessels, due to non-compliance or administrative errors from the crew in completing the surveys, or from the shipowners or the captains in distributing the surveys. On ten of the remaining vessels, surveys were only returned from one of the alternating shifts. There were on average $9.38(\mathrm{SD}=3.9)$ surveys returned from each shift. Surveys were returned from 30 platform supply vessels, thirteen emergency preparedness (a.k.a. firefighting) vessels and six anchor handling (a.k.a. rig move) vessels.

Fourteen surveys were excluded for having a high percentage of missing or non-compliant responses. For the present analysis we further filtered participants by reported nationality. The survey was written in Norwegian, and it is uncertain how well the questions were understood by crew who did not have a Scandinavian language as their first language. Further, as some variable interactions (e.g. how a crew member responds to the captain's leadership style) may be culturally contingent, including culturally diverse participants may confound effects. Therefore, only participants from the Nordic countries (Denmark, the Faroe Islands, Finland, Iceland, Norway, and Sweden) were included, while five participants from other countries and 59 participants that had neglected to state their nationality were excluded, resulting in 767 surveys. Running the analysis for a sample including the participants who did not state a nationality did not considerably change the results 
of the analysis. As one of the aims for the analysis was to examine the impact of the captain's leadership, surveys from 55 captains (and six who had not answered which position they held) were excluded from the analysis.

Our final sample thus included 705 participants. The sample consisted of vessels belonging to ten different ship-owners. The respondents were $26.6 \%$ bridge officers, $35.5 \%$ deck crew, $29.3 \%$ engine room operators, and $6.9 \%$ worked in the galley. As the responders came from relatively small crews and were distributed across different ship-owners, the survey did not ask for the respondent's sex, in order to avoid making the relatively few female responders concerned about their anonymity. For the same reason, responder's exact age was not queried, and instead age brackets were reported. Among the respondents, $23.1 \%$ were under 26 years old, $18.5 \%$ were $26-30$ years, $11.7 \%$ were $31-35$ years, $10.2 \%$ were $36-40$ years, $8.5 \%$ were $46-50$ years, $8.2 \%$ were $54-55$ years, and $7.9 \%$ were over 55 years old.

\section{2: Measures}

\subsection{1: Authentic leadership}

AL was measured with the 16-item Authentic Leadership Questionnaire (Walumbwa et al., 2008). ${ }^{1}$ This instrument measures the four components believed to comprise AL: relational transparency (e.g., "My leader admits mistakes when they are made"), moral perspective (e.g., "My leader demonstrates beliefs that are consistent with actions"), balanced processing (e.g. "My leader listens carefully to different points of view before coming to conclusions") and self-awareness (e.g., "My leader shows that he or she understands how specific actions impact others"). This measure of AL has been established as a valid and reliable instrument in other studies (Clapp-Smith et al., 2009). Respondents were asked to rate statements about the behaviours of their captain on a scale from 1 (completely disagree) to 5 (completely agree).

\footnotetext{
${ }^{1}$ It should be noted that the cited article has recently met with severe methodological criticism (see e.g. https://pubpeer.com/publications/1E79BA4AA94EB722491
}

Cronbach's $\alpha$ coefficients in the current study were .85 for "relational transparency", .79 for "moral perspective", .89 for "balanced processing", and .85 for "self-awareness".

\subsection{2: Situation awareness}

We applied a relatively new measure of trait SA (Sætrevik, 2013), where the operators answered questions about the extent to which they usually had accurate representations of the safety aspects of their work, as an indicator for the operators' confidence in their ability to carry out their work safely. The items have been developed in collaboration with subject matter experts to describe failures of perceiving, understanding or anticipating safety issues across different work-settings. The scale was designed to measure the three levels of SA separately (according to the model of Endsley, 1995). The development and validation of the scale is discussed in a previous publication (Sætrevik, 2013). The scale has 13 items with phrasing like "I sometimes lose track of safety due to receiving too much information at the same time" and "It's hard to know which consequences my actions will have for safety". Each item is rated from 1 (completely disagree) to 5 (completely agree). The scale is subdivided into three levels of SA in accordance with Endsley's (1995) classification, with four items for level $1 \mathrm{SA}$ - perception, five items for level $2 \mathrm{SA}$ - understanding, and four items for level 3 SA - projection. The scale has recently been validated on a maritime sample, and been shown to have good model fit (Sætrevik, 2013). Cronbach's $\alpha$ for the scale was .76 in the current study.

Trait measure approaches to SA have also been suggested previously. Sneddon and colleagues (2013) developed the 20 item work SA scale, partly based on the cognitive failures questionnaire (Broadbent et al., 1982). The factors affecting SA scale (Banbury et al., 2007) strives to measure the process leading to SA, and consists of 30 items with subscales on attention management, information management, cognitive efficiency, automaticity and

B14AE871B0F). We nevertheless cite it here, as the origin of our measurement tool. 
inter-personal dynamics. Also relevant is the workplace cognitive failure scale (Wallace and Chen, 2005), which has 15 items that describe slips of memory, attention or action in a wide variety of work-settings, and has been associated with safe behaviour. The question of whether a self-report trait measure is suitable for the concept of SA is addressed in section 4.3.2.

\subsection{3: Unsafe actions}

Seven items described unsafe actions that the operator could perform as part of their work on board, such as "I have been in situations where I have exposed myself or others to danger in order to get the job done" or "I have 'cut corners' with regards to safety." These were generated in collaboration with the subject matter experts in charge of developing the chartering company and the ship-owners' safety management systems. The items describe actions that are believed to occur on a regular basis, yet are in breach of safety regulations and can lead to accidents. Some of the items overlap with the safety behaviour scale developed by Rundmo (1994). Preceding the hypothesis testing, a factor analysis was done on the responses to the seven items, which revealed them to sort into two different factors with four and three items in each factor, but with no apparent theoretical clustering.

\subsection{4: Subjective risk assessment}

Participants were asked to estimate the likelihood for being exposed to each of the following seven types of incidents over the next 12 months: impact or crushing incident, stabs or cuts, poisoning, fall over board, slip or fall incident, electricity, fire or chemical incident, and crane or lifting incident. The respondents rated each incident category on a 7grade response scale $(1=$ very unlikely; $7=$ very likely). Cronbach's $\alpha$ for the scale was .89 in the current study.

\section{3: Statistical analyses}

We used structural equation modelling (SEM) to test our proposed hypotheses. In SEM analysis of full latent variables, it is important to first verify the validity of the measurement portion of the model (Byrne, 2013). Our first step was therefore to conduct confirmatory factor analysis to establish good fit for the measurement model. We used subscale mean scores as indicators for the latent $\mathrm{AL}$ and SA variables. In addition, we formed item parcels for use as indicators for the latent variables subjective risk assessment and unsafe actions. Based on the recommendations of Bandalos and Finney (2001), three parcels were formed by combining items with the highest level of congruence within the subjective risk assessment dimension (two parcels combining two items each and one parcel combining three items). Similarly, for the unsafe actions dimension, we constructed three parcels by combing three items into one parcel and the remaining four items into two separate parcels. Although item parcelling is not without controversy (Bandalos and Finney, 2001), we find the use of item parcels in the present study defensible given that our primary interest is on the structural associations rather than the measurement parameters.

After confirming a good fit for the measurement model, we proceeded to assess the full structural model and examine the proposed theoretical relationships. Model fit was judged by examining the magnitude and statistical significance of factor loadings and a series of commonly used goodnessof-fit statistics. Specifically, to assess model fit we used the comparative fit index (CFI), the TuckerLewis index (TLI), and the root mean square error of approximation (RMSEA), together with its $90 \%$ confidence interval. The chi-square measure of absolute fit is known to be overly sensitive and often signal statistically significant misfit even for trivial departures from perfect fit (Kelloway, 1995). A normed $\chi^{2}$, defined as the $\chi^{2}$ divided by $d f$, is often used in lieu of $\chi^{2}$ due to the sensitivity of the $\chi^{2}$ to sample size. The confirmatory factor analysis and structural equation modelling were performed using Stata version 13.1.

\section{3: Results}

A CFA with four inter-correlated factors was specified in a preliminary analysis to assess the 
measurement part of our model. Results from this CFA yielded a $\chi^{2}=137.59(d f=59), \chi^{2} / d f=2.33$, a $\mathrm{CFI}=.98, \mathrm{a}$ TIL $=.97$ and $\mathrm{a}$ RMSEA $=.043(90 \%$ $\mathrm{CI}=.034-.053)$. RMSEA values below .08 and CFI and TLI values above .95 are often considered to represent acceptable fit to the data $(\mathrm{Hu}$ and Bentler, 1999; Kline, 1998; McDonald and Ho, 2002). Normed $\chi^{2}$ values close to 2 are often recommended as indicating reasonable fit, although it should be noted that no clear-cut guideline exist about what constitutes an acceptable value of the normed $\chi^{2}$ (Bollen, 1989). Our goodness-of-fit indexes and normed $\chi^{2}$ thus all indicated an acceptable fit to the data, and we therefore proceeded to test the full structural model.
Our full structural model demonstrated good fit to the data and is presented in Figure 1. As proposed in hypotheses $\mathrm{H} 1$ and $\mathrm{H} 2$, increases in $S A$ were associated with decreases in unsafe actions $(\beta=-$ $.52, z=-10.49, p<.001)$ and subjective risk assessment $(\beta=-.31, z=-7.61, p<.001)$. In accordance with $\mathrm{H} 3$ and $\mathrm{H} 4$, increases in $A L$ were related to declines in unsafe actions $(\beta=-.17, z=-$ $3.42, p=.001)$ and increases in $S A(\beta=.39, z=9.71$, $p<.001)$. The final model accounted for $15 \%$ of the variation in $S A, 37 \%$ of the variation in unsafe actions, and $10 \%$ of the variation in subjective risk assessment.

Figure 1: Results from SEM analysis

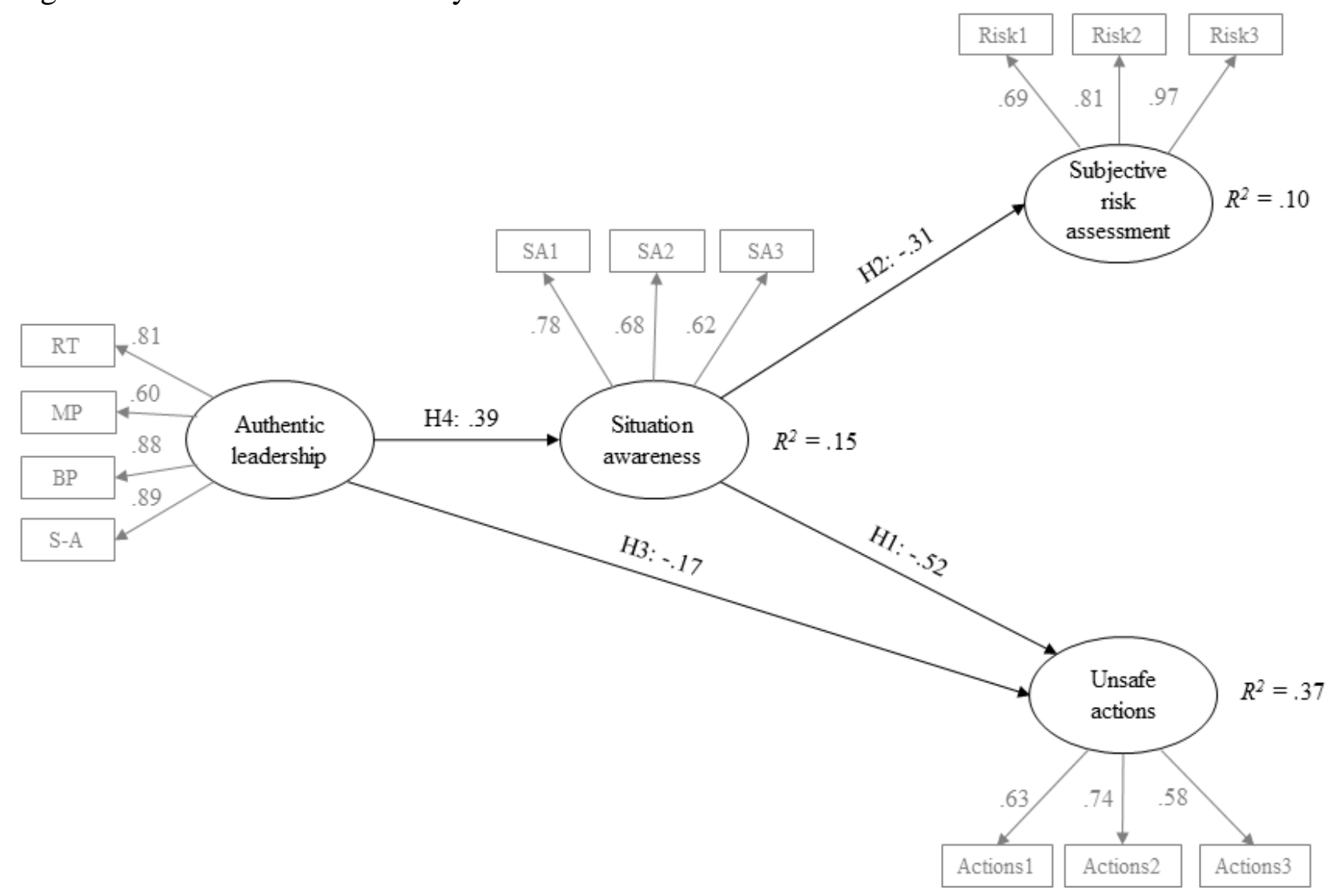

Results from a structural equation model testing the four hypothesized relations (H1-H4) between authentic leadership, situation awareness, unsafe actions, and subjective risk assessment. RT = Relational transparency; $\mathrm{MP}=$ Moral perspective; $\mathrm{BP}=$ Balanced processing; $\mathrm{S}-\mathrm{A}=$ Self-awareness. Error terms and endogenous disturbances have been omitted for space and clarity. Chi-square $=142.40, d f=61, p<.001 ; \chi^{2} / d f=2.33 ; \mathrm{CFI}$ $=.98 ; \mathrm{TLI}=.97 ; \mathrm{RMSEA}=.044,90 \% \mathrm{CI}=.034-.053$. 


\section{4: Discussion}

\section{1: Summary of results}

The aim of the present study was to examine the role that SA plays as a determinant for unsafe actions and subjective risk assessment, under the assumption that this would be associated with reduced safety in a petro-maritime setting. To achieve this, survey questionnaires were collected from the crew of 49 different vessels on variables of AL, SA, unsafe actions and subjective risk assessment.

All the proposed hypotheses were supported. An increase in $S A$ was shown to have a negative loading on self-report of unsafe actions (H1), and on the respondent's subjective risk assessment (H2). An increase in $A L$ was shown to have a negative loading on self-report of unsafe actions (H3) and a positive loading on $S A(\mathrm{H} 4)$.

\section{2: Contribution from the factors in the model}

\subsection{1: Effects of situation awareness}

It has often been argued that SA is "at the sharp end" of unwanted incidents in high-reliability organizations (Flin et al., 2008), in the sense that accidents may have been prevented or mitigated if the operators would have had a better understanding of their environments. Thus, it is argued that the operator's level of SA is the final human safety barrier that prevents an incident potential to develop into an actual accident. For example, if a vessel is on a collision course, there may be various indicators of this that the helmsman can notice and understand, and take the appropriate action in time to prevent a collision. When an accident occurs, it may be due to an operator not being able to perceive important information, not creating an accurate mental model of the situation, or not predicting how the situation was about to develop. However, one should note that to point to a SA deficiency as a final determinant for an incident is not to say that the operator is responsible or should be blamed for the incident. This is because the SA deficiency may itself be caused by a number of factors outside the operator's control, such as poor workplace design, lack of training, an unrealistic task load, et cetera (Dekker, 2002; Dekker et al., 2010). It should further be noted that as accidents are overdetermined (Reason, 1990), they may still arise even if the operator's SA is accurate.

A crucial finding of the current study was that in line with $\mathrm{H} 1$, variation in SA accounted for variation in unsafe actions. This indicates that operators who report that they are able to maintain an overview of potential dangers in their task environment also respond that they carry out their work-tasks more safely (i.e. according to the vessel's safety management system). The association could be due to features of the work that allows for easier perception of safety critical information, which allows operators to better mentally represent the situation, and predict how threats may develop over time, thus creating more accurate SA that leads to safer work. This may be facilitated by the structural aspects of the workplace, such as the placement of equipment and information sources, by features of the work-organization, such as the organizational safety culture, the manpower, the distribution of tasks and the amount of training offered, or by individual factors, such as variation in experience, cognitive capacity or individual attitudes to safety. Inaccurate $\mathrm{SA}$ is often identified as a causal factor in accident investigations in a broad spectrum of settings, including the offshore maritime industry (see e.g. Roberts et al., 2015). Stanton and colleagues (2001) further discuss the relationship between SA and safety. In some cases, accident reports can be broken down according to whether the accident was caused by having inaccurate SA perception, SA understanding, or SA prediction (Sneddon et al., 2012). However, due to not having suitable measures for large-scale data collection, it has to little extent been identified as an a priori predictor of safety conditions. The current study supported the assumption that SA is a "sharp end" causal factor for human error.

The study also showed that variation in SA accounted for variation in subjective risk assessment, in line with $\mathrm{H} 2$. In other words, operators that are confident that they have an overview of the safety aspects of their work also feel 
that they are less likely to be exposed to accidents. This feeling of safety may be founded in an accurate SA that actually safeguards the operators through the mechanisms outlined above. Thus operators that have a more accurate SA may in fact be less likely to be exposed to accidents, due to being aware of indicators of dangers, or due to being able to handle critical situations better. An operator with less accurate SA may experience more near-misses, and thus see the workplace as riskier. Further, the factors that contribute to an operator's SA may in part be shared with his or her co-workers, and an operator that reports having accurate SA may thus feel less exposed to accidents caused by co-workers. However, the association could also result from an overly high or low confidence in the operators' ability to maintain an overview of their work that does not directly impact actual safety.

Some of the items in our $S A$ measure may overlap with items in the work SA rating tool (Sneddon et al., 2013) that describe cognitive failures (such as items about being distracted, and planning for different outcomes). However, other items in the work SA rating tool relates to physical actions and may resemble our unsafe actions measure (such as items about committing errors, acting without thinking or "working on auto-pilot"). While comparisons between the two tools may be useful, we see value in distinguishing the cognitive processes from the physical actions, and our analysis suggests that the former may cause the latter.

\subsection{2: Effects of authentic leadership}

In line with $\mathrm{H} 3$, the current study showed an effect of AL on unsafe actions, in the sense that operators who considered their captains to be authentic leaders reported committing fewer unsafe actions. An authentic captain would be expected to prioritize safety and to act in accordance with these priorities. By acting as models, authentic leaders will increase the followers' levels of self-awareness and selfregulation, which in turn should lead to positive outcomes for follower behaviour and the organisation as a whole. Further, the captain's behaviours could contribute in a more direct manner through improving the work-environment in a way that enhances safety, for example by removing distracting factors, managing for optimal workload or effectively sharing key information with the operators.

The relationship between AL and unsafe actions can also be due to this leadership style being more effective in motivating the operators to follow the safety procedures through making operators internalize the company's safety values as their own values and acting accordingly. Hystad and colleagues (2014) have argued for such a relationship, suggesting that authentic leaders influence followers to adopt similar attitudes and behaviours through role modelling and social identification processes. Captains who are authentic, in the sense that they are seen to act in accordance with their professed safety values and are seen as genuine by the crew when they encourage safety, may provide a model for social learning for the crew. Such learning may cause the crew to adopt the company standards for careful work and safe conduct. Similar effects of internalizing the leader's professed values have been seen in other settings, such as the restaurant industry (Barling et al., 2002) and the educational system (Van Dick et al., 2007).

Trust is another mechanism that may link AL to follower's safe behaviour. Gardner and colleagues (2005) maintained that authentic leader-follower relations would increase trust. For example, authentic leaders who engage in balanced processing of information in decision-making rather than making snap decisions may foster a trusting relationship with followers because this behaviour demonstrates consideration and willingness to accommodate the followers' viewpoints. Similarly, Clapp-Smith and colleagues (2009) found authentic leadership to predict employee trust in management in a sample of workers in the retail industry. Trust is in turn recognized as an important element of effective safety cultures in high-reliability organizations (Burns et al., 2006; Reason, 1997). Kramer (1999) reviewed the literature on trust in organisations and reported that trust fosters cooperation between individuals, extra-role behaviour, information sharing and work towards 
common goals, to name a few. Extended to highreliability organisations, it is reasonable to argue that trust in leaders can results in followers who are more inclined to follow prescribed safety regulations and to work in a safe manner.

In line with $\mathrm{H} 4$, the current study also showed that the operators' SA was associated with their rating of their captains' AL. AL thus has both a direct effect on safety (H3), in addition to the indirect effect through affecting SA, which in turn affects safety (discussed as $\mathrm{H} 1$ and $\mathrm{H} 2$ above). The direct effect of AL may work through the captain being seen as a model for safety behaviour as well as providing specific guidance. Part of the effect of AL may also be due to the captain making the operators more motivated to pay attention, to be more vigilant in their day-to-day tasks, and to direct their attention to the aspects of the environment most relevant for safety. An authentic captain can also encourage operators to invest in learning about safety issues in their environment, and to make a habit of thinking ahead in how potential threats may develop over time. It could also be that an authentic captain more frequently discusses safety issues with the crew and makes sure that the crew are up-to-date on safety issues, which may make the crew more confident in their SA on safety aspects.

\section{3: Implications of study}

The current study showed that AL has effects on SA and in turn on unsafe actions and on subjective risk assessment. The most potent effects were those of $S A$ on unsafe actions and $A L$ on $S A$, and secondary, of $S A$ on subjective risk assessment, while the effect of $A L$ on unsafe actions was weaker.

\subsection{1: AL and SA in applied settings}

Small-scale experimental studies (Sarter and Woods, 1994; Wright et al., 2004) have previously indicated that inaccurate SA may cause human error in safety critical work. However, typical SA measurement approaches are limited by needing to construct an artificial situation to measure SA, subjective evaluations of the operators or observers, and the need for a "ground truth" to measure responses or actions against. There are also small- scale field studies of SA (see e.g. Matthews and Beal, 2002; Patrick et al., 2006; Strater et al., 2001; Sætrevik and Eid, 2014), which use observational method or freeze probes. These have higher ecological validity and may avoid the problem of a ground truth, but have issues of validity, generalizability and accounting for confounding factors (for reviews of approaches to measuring SA, see Salmon et al., 2006; Saner et al., 2009). The current study indicates that a trait SA measure can be used in large-scale data collections to predict unsafe actions and subjective risk assessment. This complements other approaches to trait measures of SA, such as the aforementioned work by Sneddon and colleagues (2013).

High-reliability organizations with high stakes such as the petro-maritime vessels studied here could benefit from interventions aimed at increasing SA. The study indicates that increasing the captains' AL may be one route to increase the crews' SA. There is empirical evidence showing that developing AL is possible. Baron (2012) describes a training program in which leaders receive structured peer coaching and planned trigger-events aimed towards developing AL. Trigger-events are situations and challenges designed to promote individual growth and development, for example by enabling participants to reframe their conventional ways of acting and thinking. The training program described by Baron lasts three years and would thus be a relatively long-term investment. It is however worth mentioning that there is only 15 days of training each year, and increases in AL were seen after the first year. Qualitative studies (Choudhry and Fang, 2008; Mullen, 2004) have indicated that safety may be influenced by work-environment factors such as work-pressure, co-workers' attitudes, safety culture, management, procedures, training, as well as other social, organizational and economic factors.

\subsection{2: Limitations}

The study used self-report data-collection at a single time-point without external measures, which has some inherent weaknesses. Some of these weaknesses are associated with self-serving bias, or working from imperfect memory. In particular for 
measures of $S A$ and recent accidents, one cannot report what one does not know, for example if one is ignorant of one's own inaccurate representation of safety information, or are unaware of near-miss incidents that have occurred. It has been argued (Endsley, 1994; Rousseau et al., 2010) that selfreports measure the operator's confidence in their SA, rather than the accuracy of SA. While such caveats should be considered, it is difficult to test possible associations in a company-wide sample without using self-report.

SA is usually measured as the accuracy of the mental representation for a given setting, and hence tends to be measured for a set space and time (i.e. a state measurement). Typical measures ask for selfreports of SA confidence or measure knowledge accuracy about the scenario in a dedicated experiment, a simulator training exercise or in a field study where a given task is performed (for reviews on measurement approaches, see Patrick and Morgan, 2010; Salmon et al., 2006; Saner et al., 2009; Sætrevik and Eid, 2014). Thus the "awareness" in SA is usually directed at a specific situation, while the current SA measure is related to being aware of safety issues across different situations, and over some time (i.e. the items are interpreted as "how aware are you usually"). It could be argued that the current approach to measuring $\mathrm{SA}$ as an individual trait that can be queried in a context-general survey is not suitable, as SA is not constant to the individual but changes between different settings. We would argue that measuring SA as a trait may be valid under the assumption that some aspects of SA are constant for the individual across time and across situations. While one may expect an operator's SA to vary across work-environments, some general factor could correlate with the current measure of trait SA. This would be due to SA relying on the individual's cognitive capacities, personality, motivation, attitudes and experience, as well as environment factors that are constant for the individual (e.g. working on a vessel that facilitates SA). This should not be taken to indicate that we see SA as wholly determined by individual factors, or that it cannot be changed by experience. Rather, SA emerges through the operator's interplay with the setting, and can increase with experience, training or changes to the work-environment. Thus the current measure could be seen as a proxy for the actual SA as the term is traditionally used in the literature. This is further discussed in a previous publication (Sætrevik, 2013). The current approach is one of necessity, as state measures of SA will be unsuited for use in a large-scale survey data collection. Further, the present results indicate that our SA measure has theoretically meaningful associations with other variables believed to be relevant for safety.

Given that the study uses a single time-point measurement, the causal relationship between the variables should be considered with some care. Such concerns are typical in survey research, and are sometimes referred to as the "common method bias" (Podsakoff et al., 2003). To exclude these caveats, a preferred design would be to measure $\mathrm{AL}$ and SA at one time, and measure the subjective risk assessment and unsafe actions (or actual incidents) at a later time. Such ideal studies tend to be difficult to perform in the current setting.

The association between $S A$ and subjective risk assessment could be due to more optimistic ally disposed operators responding that they both have accurate SA and think that they are unlikely to meet with an accident (however, note the opposite finding in Eid et al., 2005). Such alternative accounts are always difficult to exclude when using self-report data alone. It should be noted that the measure of perceived risk used here asks only about person accidents, such as being subject to a crane accident, and not about process accidents, such as being on board a vessel that has a collision. Thus the operator may believe that they themselves and their immediate colleagues are in control of the potential causes for the accidents that they are asked to assess, while still being at risk for accidents that are due to external events. Further, it could also be that operators that are more safety conscious more easily remember recent accidents or interpret recent situations as more risky than other operators would.

The present study aimed to address issues with relevance for actual maritime safety. The unsafe 
actions items were intended to describe actions that are likely to occur on a regular basis, that are in breach of safety management systems, and that can lead to accidents. However, the study is not able to answer whether unsafe actions correspond to an actual reduction of safety. Further, while it is typically assumed that adherence to the safety regime is predictive of safe work, it is possible that an experienced operator may interpret the regulations with some discretion without any detectable reduction in safety outcomes.

A further question is whether subjective risk assessment corresponds to actual risk. The currently presented model may account for variations in how safe operators feel in their work, but be unrelated to the actual chance of the operator or the vessel encountering an accident. To resolve this, longitudinal studies are required that measure subjective risk assessment at one time, and record the subsequent frequency of unwanted incidents. Nevertheless, one may also state that when an operator feels that they are at risk in their day-to-day work, this in itself constitutes a stressor for the operator. Further, Rundmo (1996) argued that the added stress of feeling at risk, may itself increase the objective risk. One can also imagine operators being unjustifiably optimistic about the level of safety on board, which may lead to complacency, which has the actual effect of reducing safety.

\subsection{3: Conclusions and need for further research}

The current study has indicated that a new survey measure of trait SA accounts for accident causation in high-reliability organizations. This warrants further work in identifying the predictors of SA. Being able to approach SA through a survey approach allows large-scale data collection on this issue, and to explore the impact of organizationlevel interventions. Relevant factors to explore could be safety training, interventions for attitude change or safety climate, changes to shift-work regiments, and the impact of company or government safety regulations.

Given the limitations of the current study discussed above, future studies should strive to include longitudinal measurements, where the proposed predictors (e.g. AL) measured at one point in time is seen to have effects on outcome measures (e.g. SA or subjective risk assessment) at a later point in time. Independent studies with objective outcome measures are required to test whether the current measure with self-report of actions corresponds to actually performing unsafe actions in day-to-day work. Further, studies in this field would increase their validity if they could measure objective safety indicators, rather than the crew's subjective risk assessment or self-report of incidents and actions. Accidents are rare, but given largescale data-collection in arenas that also records small accidents and near-miss incidents, it should be possible to align survey data with recorded accident frequency.

\section{Acknowledgments}

The data collection was done in collaboration with and supported by the Marine operations department of Statoil's Development and Production Norway, Logistics and Emergency preparedness. Some of the survey items were developed in collaboration with subject matter experts at Statoil and at the relevant ship owner companies. The ship owner companies on hire for Statoil contributed in the data collection, and we are grateful to the vessel crews for taking time to answer the survey.

\section{References}

Banbury, S., Dudfield, H., Hoermann, H.-J., Soll, H., 2007. FASA: Development and validation of a novel measure to assess the effectiveness of commercial airline pilot situation awareness training. The International Journal of Aviation Psychology 17, 131-152.

Bandalos, D.L., Finney, S.J., 2001. Item parceling issues in structural equation modeling, New developments and techniques in structural equation modeling. Lawrence Erlbaum, Mahwah, NJ, pp. 269-296.

Barling, J., Loughlin, C., Kelloway, E.K., 2002. Development and test of a model linking safety-specific transformational leadership and occupational safety. Journal of Applied Psychology 87, 488.

Baron, L., 2012. Developing authentic leadership through experiential training: An empirical study, Academy of Management Proceedings. Academy of Management, pp. $1-1$.

Bollen, K., 1989. Structural equations with latent variables. John Wiley \& Sons, New York. 
Broadbent, D.E., Cooper, P.F., FitzGerald, P., Parkes, K.R., 1982. The cognitive failures questionnaire (CFQ) and its correlates. British journal of clinical psychology 21, 1-16.

Bureau of Safety and Environmental Enforcement, 2016. Incident Statistics and Summaries.

Burns, C., Mearns, K., McGeorge, P., 2006. Explicit and implicit trust within safety culture. Risk Analys is 26, 11391150.

Byrne, B.M., 2013. Structural equation modeling with EQS: Basic concepts, applications, and programming. Routledge.

Chiappe, D.L., Strybel, T.Z., Vu, K.-P.L., 2012. Mechanisms for the acquisition of situation awareness in situated agents. Theoretical Issues in Ergonomics Science 13, 625-647.

Choudhry, R.M., Fang, D., 2008. Why operatives engage in unsafe work behavior: Investigating factors on construction sites. Safety Science 46, 566-584.

Clapp-Smith, R., Vogelgesang, G.R., Avey, J.B., 2009. Authentic leadership and positive psychological capital the mediating role of trust at the group level of analysis. Journal of Leadership \& Organizational Studies 15, 227 240.

Clarke, S., 2013. Safety leadership: A meta-analytic review of transformational and transactional leadership styles as antecedents of safety behaviours. Journal of Occupational and Organizational Psychology 86, 22-49.

Dekker, S.W., 2002. Reconstructing human contributions to accidents: the new view on error and performance. Journal of Safety Research 33, 371-385.

Dekker, S.W.A., Hummerdal, D.H., Smith, K., 2010. Situation awareness: some remaining questions. Theoretical Is sues in Ergonomics Science 11, 131-135.

Eid, J., Matthews, M.D., Meland, N.T., Johnsen, B.H., 2005. Dispositional optimism and self-assessed situation awareness in a Norwegian military training exercise. Perceptual and Motor Skills 100, 649-658.

Endsley, M.R., 1994. Situation awareness in dynamic human decision making: Measurement, In: Gilson, R.D., Garland, D.J., Koonce, J.M. (Eds.), Situational awareness in complex systems. Embry-Riddle Aeronautical University Press, Daytona Beach, FL, pp. 79-97.

Endsley, M.R., 1995. Toward a theory of situation awareness in dynamic systems. Human Factors: The Journal of the Human Factors and Ergonomics Society 37, 32-64.

Endsley, M.R., 2004. Situation awareness: Progress and directions. A cognitive approach to situation awareness: Theory, measurement and application, 317-341.

Endsley, M.R., Jones, W.M., 2013. Situation awareness. The Oxford Handbook of Cognitive Engineering, 88-108.

Flin, R.H., Mearns, K., Gordon, R., Fleming, M., 1996. Risk perception by offshore workers on UK oil and gas platforms. Safety Science 22, 131-145.

Flin, R.H., O'Connor, P., Crichton, M., 2008. Safety at the sharp end: a guide to non-technical skills. Ashgate Publishing, Ltd.
Gardner, W.L., Avolio, B.J., Luthans, F., May, D.R., Walumbwa, F., 2005. "Can you see the real me?" A selfbased model of authentic leader and follower development. The leadership quarterly 16, 343-372.

Hone, G., Martin, L., Ayres, R., 2006. Awareness - does the acronym "SA" still have a practical value?, 11th International Command and control research and technology symposium, Cambridge, UK.

Hu, L.t., Bentler, P.M., 1999. Cutoff criteria for fit indexes in covariance structure analys is: Conventional criteria versus new alternatives. Structural equation modeling: a multidisciplinary journal $6,1-55$.

Hystad, S.W., Bartone, P.T., Eid, J., 2014. Positive organizational behavior and safety in the offshore oil industry: Exploring the determinants of positive safety climate. The journal of positive psychology 9, 42-53.

International Association of Oil and Gas Producers, 2014. Safety performance indicators - 2013 data (Report No. 2013s).

Kelloway, E.K., 1995. Structural equation modelling in perspective. Journal of Organizational Behavior 16, 215 224.

Kirschenbaum, A., Oigenblick, L., Goldberg, A.I., 2000. Well being, work environment and work accidents. Social Science \& Medicine 50, 631-639.

Klein, G., Moon, B., Hoffman, R.R., 2006. Making sense of sensemaking 1: Alternative perspectives. IEEE intelligent systems, 70-73.

Kline, R.B., 1998. Software review: Software programs for structural equation modeling: Amos, EQS, and LISREL. Journal of psychoeducational as sessment 16, 343-364.

Kramer, R.M., 1999. Trust and distrust in organizations: Emerging perspectives, enduring questions. Annu Rev Psychol 50, 569-598.

Matthews, M.D., Beal, S.A., 2002. Assessing situation awareness in field training exercises. DTIC Document.

McDonald, R.P., Ho, M.-H.R., 2002. Principles and practice in reporting structural equation analyses. Psychological methods 7, 64 .

Mullen, J., 2004. Investigating factors that influence individual safety behavior at work. Journal of Safety Research 35, 275-285.

Nielsen, M.B., Eid, J., Mearns, K., Larsson, G., 2013. Authentic leadership and its relationship with risk perception and safety climate. Leadership and Organization Development Journal 34, 308-325.

Patrick, J., James, N., Ahmed, A., Halliday, P., 2006. Observational assessment of situation awareness, team differences and training implications. Ergonomics 49, 393 417.

Patrick, J., Morgan, P.L., 2010. Approaches to understanding, analysing and developing situation awareness. Theoretical Is sues in Ergonomics Science 11, 41-57.

Podsakoff, P.M., MacKenzie, S.B., Lee, J.-Y., Podsakoff, N.P., 2003. Common method biases in behavioral research: a critical review of the literature and 
recommended remedies. Journal of Applied Psychology $88,879$.

Probst, T.M., Brubaker, T.L., Barsotti, A., 2008. Organizational injury rate underreporting: the moderating effect of organizational safety climate. J Appl Psychol 93, 1147-1154.

PubPeer, n.d. PubPeer > Journal of Management "Authentic Leadership: Development and Validation of a TheoryBased Measure".

Reason, J., 1990. Human error. Cambridge university press, New York.

Reason, J., 1997. Managing the Risks of Organizational Accidents. Ashgate Publishing Company, Aldershot.

Roberts, R., Flin, R., Cleland, J., 2015. "Everything was fine"*: An analysis of the drill crew's situation awareness on Deepwater Horizon. Journal of Loss Prevention in the Process Industries 38, 87-100.

Rousseau, R., Tremblay, S., Banbury, S., Breton, R., Guitouni, A., 2010. The role of metacognition in the relationship between objective and subjective measures of situation awareness. Theoretical Issues in Ergonomics Science 11, 119-130.

Rundmo, T., 1994. Associations between safety and contingency measures and occupational accidents on offshore petroleum platforms. Scandinavian Journal of Work, Environment \& Health, 128-131.

Rundmo, T., 1996. Associations between risk perception and safety. Safety Science 24, 197-209.

Salmon, P.M., Stanton, N.A., Walker, G., Green, D., 2006. Situation awareness measurement: a review of applicability for C4i environments. Applied Ergonomics 37, 225-238.

Saner, L.D., Bolstad, C.A., Gonzalez, C., Cuevas, H.M., 2009. Measuring and predicting shared situation awareness in teams. Journal of Cognitive Engineering and Decision Making 3, 280.

Sarter, N.B., Woods, D.D., 1991. Situation awareness: A critical but ill-defined phenomenon. The International Journal of Aviation Psychology 1, 45-57.

Sarter, N.B., Woods, D.D., 1994. Pilot interaction with cockpit automation II: An experimental study of pilots' model and awareness of the flight management system. The International Journal of Aviation Psychology 4, 1-28.

Sneddon, A., Mearns, K., Flin, R., 2006a. Safety and situation awareness:" Keeping the Bubble" in offshore drilling crews, SPE International Health, Safety \& Environment Conference. Society of Petroleum Engineers.
Sneddon, A., Mearns, K., Flin, R., 2006b. Situation awareness and safety in offshore drill crews. Cognition, Technology \& Work 8, 255-267.

Sneddon, A., Mearns, K., Flin, R., 2012. Stress, fatigue, situation awareness and safety in offshore drilling crews. Safety Science 56, 80-88.

Sneddon, A., Mearns, K., Flin, R., 2013. Stress, situation awareness and safety in offshore drilling crews. Safety Science 56, 80-88.

Stanton, N.A., Chambers, P., Piggott, J., 2001. Situational awareness and safety. Safety Science 39, 189-204.

Stanton, N.A., Salmon, P.M., Walker, G.H., 2015. Let the Reader Decide: A Paradigm Shift for Situation Awareness in Sociotechnical Systems. Journal of Cognitive Engineering and Decision Making 9, 44-50.

Strater, L.D., Endsley, M.R., Pleban, R.J., Matthews, M.D., 2001. Measures of platoon leader situation awareness in virtual decision-making exercises. DTIC Document.

Sætrevik, B., 2013. Developing a context-general self-report approach to measure three-level situation awareness. International maritime health 64, 66-71.

Sætrevik, B., Eid, J., 2014. The 'similarity index' as an indicator of shared mental models and situation awareness in field studies. Journal of Cognitive Engineering and Decision Making 8, 119-136.

Van Dick, R., Hirst, G., Grojean, M.W., Wieseke, J., 2007. Relationships between leader and follower organizational identification and implications for follower attitudes and behaviour. Journal of Occupational and Organizational Psychology 80, 133-150.

van Winsen, R., Dekker, S.W.A., 2015. SA Anno 1995: A Commitment to the 17th Century. Journal of Cognitive Engineering and Decision Making 9, 51-54.

Wallace, J.C., Chen, G., 2005. Development and validation of a work-specific measure of cognitive failure: Implications for occupational safety. Journal of Occupational and Organizational Psychology 78, 615-632.

Walumbwa, F.O., Avolio, B.J., Gardner, W.L., Wernsing, T.S., Peterson, S.J., 2008. Authentic leadership: Development and validation of a theory-based measure. Journal of Management 34, 89-126.

Weddle, M.G., 1996. Reporting occupational injuries: The first step. Journal of Safety Research 27, 217-223.

Wright, M., Taekman, J., Endsley, M., 2004. Objective measures of situation awareness in a simulated medical environment. Quality and safety in health care 13, i65-i71. 